\title{
Synthesis and characterization of hybrid cured poly(ether-urethane)acrylate/titania microcomposites formed from tetraalkoxytitanate precursor
}

\author{
A. L. Tolstov ${ }^{*}$, V. F. Matyushov ${ }^{1}$, D. O. Klymchuk ${ }^{2}$ \\ ${ }^{1}$ Institute of Macromolecular Chemistry, National Academy of Sciences of Ukraine \\ 48 Kharkivske shose, 02160 Kyiv, Ukraine \\ ${ }^{2}$ N.G. Kholodny Institute of Botany, National Academy of Sciences of Ukraine \\ 2 Tereshchenkivska str., 01601 Kyiv, Ukraine
}

Received 17 March 2008; accepted in revised form 26 April 2008

\begin{abstract}
Hybrid poly(ether-urethane)acrylate (PEUA)/titania $\left(\mathrm{TiO}_{2}\right)$ microcomposites were prepared using a novel method that includes a swelling of different photo-crosslinked PEUA networks in concentrated tetraisopropoxytitanate $\left(\mathrm{Ti}\left(\mathrm{OiC}_{3} \mathrm{H}_{7}\right)_{4}\right.$ or TIPT) precursor solution in organic media followed by the hydrolysis of covalently bonded polyalkoxytitanate $\left(\left[-\mathrm{OTi}\left(\mathrm{OC}_{3} \mathrm{H}_{7}\right)_{2}-\right]_{\mathrm{n}}\right)$ chains and their aggregation to amorphous micro- and nano-scale sized $\mathrm{TiO}_{2}$ particles. A formation of polymer/titania hybrids was confirmed by complex investigations of the hybrids using infrared (IR) spectroscopy, small angle X-ray scattering (SAXS) analysis, scanning electron microscopy (SEM) and gravimetry. The dependence of titania phase formation behavior versus functionality of the poly(ether-urethane)acrylate network was discussed. The presence of reactive groups in the organic network promotes the formation of surface-bonded ball-shaped type $\mathrm{TiO}_{2}$ inclusions as well as provides transparency to the hybrid film samples. The results obtained in this work can be applied for the development of polymer/ $\mathrm{TiO}_{2}$ composite materials for multipurpose optical application and advanced sealants.
\end{abstract}

Keywords: polymer composites, hybrids, titania, material testing

\section{Introduction}

Nowadays a great interest of many leading scientists in the world is attracted by perspective highperformance hybrid organo-inorganic polymer composite materials because of their multiple applications. Typically, for the composites (including hybrid composites) preparation the different dispersed substances, like metals $(\mathrm{Ag}, \mathrm{Au}, \mathrm{Cu}, \mathrm{Pt})$ $[1,2]$, carbon [3], clays [4], $\mathrm{CaCO}_{3}[5]$, alumina [1], silica [1, 6, 7], titania $\left(\mathrm{TiO}_{2}\right)[1,8-14]$ and others could be used. The polymer/titania composites are one of the most widespread due to their multifarious application fields, such as adhesives and sealants [8], high-refractive thin films [9], photo- catalysts [11], composite solid polymer electrolytes for Li-batteries [13] or solar cells [14, 15]. Basic methods of the polymer/titania composites preparation could be presented as follows: (1) formation of polymer materials with introduced fine-dispersed commercial $\mathrm{TiO}_{2}[8]$ or commercially available stabilized titania suspension [16], (2) self-made relatively stable $\mathrm{TiO}_{2}$ sol preparation followed by incorporation into polymer matrix $[10,17,18]$, or (3) condensation of different functional organotitanium monomers followed by their polymerization until the linear $\mathrm{TiO}_{2}$-containing oligomers or polymer networks are formed [19]. 
Here another perspective way was proposed for the preparation of hybrid poly(ether-urethane)acrylate (PEUA)/titania microcomposites. Photo-cured poly(ether-urethane)acrylates were swollen in concentrated tetraisopropoxytitanate $\left(\mathrm{Ti}\left(\mathrm{OiC}_{3} \mathrm{H}_{7}\right)_{4}\right.$ or TIPT) solutions in organic media followed by exhaustive hydrolysis of the covalently bonded precursor into titania aggregates. The microcomposites prepared were studied thoroughly using infrared (IR) spectroscopy, small angle X-ray scattering (SAXS) technique, scanning electron microscopy (SEM), gravimetry.

\section{Experimental section}

\subsection{Materials}

Oligooxypropylenes (OOP) with different functionalities (hydroxyl-terminated) having molecular weights of 2000 (bifunctional) and 5000 (trifunctional) (OOP2000-2 and $\mathrm{OOP}^{5000-3}$, correspondingly) were taken as the oligoether component of the poly(ether-urethane)acrylates and were used as received. Commercial toluene diisocyanate (TDI) (mixture of 2,4- and 2,6-isomers with 80/20 ratio), hexamethylene diisocyanate (HMDI), ethylene gly- col monomethacrylic ester (MEG), acrylic acid (AA), methyl methacrylate (MMA) and tertaisopropoxytitanate, $\mathrm{Ti}\left(\mathrm{OiC}_{3} \mathrm{H}_{7}\right)_{4}$, (all from Aldrich Chemicals) were additionally purified by distillation at reduced pressure. Dicyclohexyl ketone (DCHK) has been used as a photoinitiator for PEUA curing without any purification. As solvents and swelling agents the chemical grade 2-propanol (2-P) or 1,4-dioxane (1,4-D) were used. As an extractive solvent for gel fraction determination pure acetone has been applied.

\subsection{Preparation of poly(ether-urethane)acrylates}

Poly(ether-urethane)acrylates of different structures, functionalities (terminal acrylic unsaturation) and molecular weights based on corresponding oligoethers, TDI or HMDI and MEG were synthesized using a method that is similar with one described in [20]. Composition and main characteristics of the PEUA prepared are summarized in Table 1. Schematically the PEUA macromolecules architecture and their definite terminal acrylic functionality were presented in Figure 1.

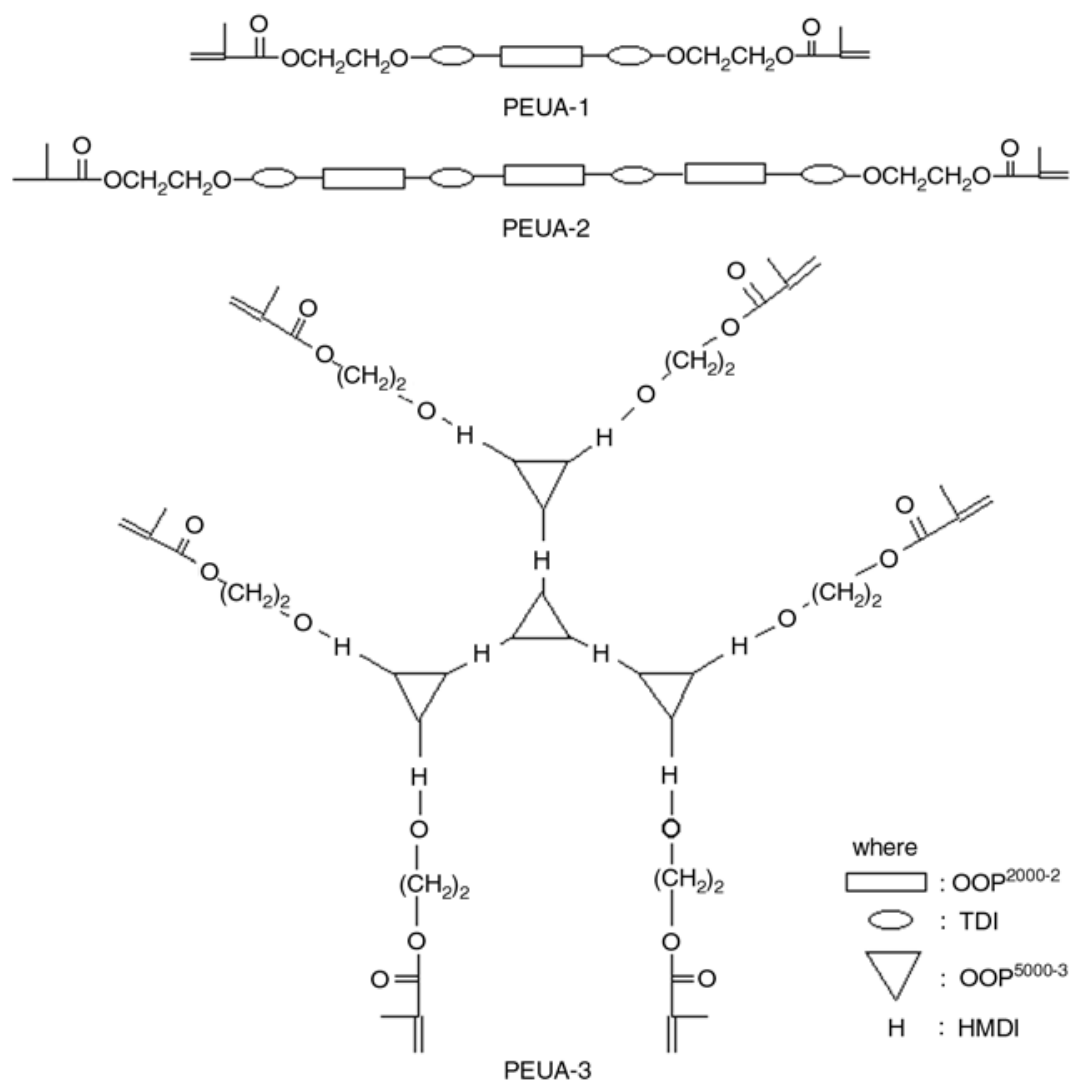

Figure 1. Schematic molecular architecture of PEUA synthesized 
Table 1. Composition and basic characteristics of uncured poly(ether-urethane)acrylates synthesized

\begin{tabular}{|c|c|c|c|c|}
\hline Sample & Composition & Molar components ratio & $\mathbf{M}_{\mathbf{w}}(\mathbf{v i s c o s i m e t r y})$ & Molecular structure \\
\hline PEUA-1 & OOP $^{2000-2} / \mathrm{TDI} / \mathrm{MEG}$ & $1 / 2 / 2$ & 2500 & linear \\
\hline PEUA-2 & $\mathrm{OOP}^{2000-2} / \mathrm{TDI} / \mathrm{MEG}$ & $3 / 4 / 2$ & 7000 & linear \\
\hline PEUA-3 & $\mathrm{OOP}^{5000-3} / \mathrm{HMDI} / \mathrm{MEG}$ & $4 / 9 / 6$ & - & hyper-branched \\
\hline
\end{tabular}

\subsection{Photo-curing PEUA}

Functionalized poly(ether-urethane)acrylate networks were synthesized from corresponding PEUA, AA and MMA by typical photo-initiated copolymerization process [21] using DCHK photoinitiator and film samples of $0.5 \mathrm{~mm}$ thickness were obtained. The components ratio of the PEUA/ AA/MAA composite samples was 60/10/30 (by weight). The free pendant $\mathrm{COOH}$ groups (presence is caused by AA constituent) in the poly(ether-urethane)acrylate networks are necessary to be the covalent junction points between organic poly(ether-urethane)acrylate constituent and inorganic titania component of the composites prepared. As a comparative non-functionalized (without free pendant carboxyl groups) sample the PEUA/MAA $=60 / 40$ (by weight) was also prepared.

\subsection{Preparation of polymer/titania hybrids}

For preparation of hybrid polymer/titania microcomposites the poly(ether-urethane)acrylate networks were swollen in $50 \%$ (by weight) TIPT solution in 2-propanol or 1,4-dioxane at ambient temperature for definite time. Swelling ratio values for each PEUA network sample were calculated by Equation (1):

$$
S R=\left(\frac{100 m_{s}}{m_{0} q}-1\right) \cdot 100 \%
$$

where $S R, m_{0}$ and $m_{s}$ are the swelling ratio [\%], film weight before swelling $[\mathrm{g}]$ and swollen film weight [g], respectively, $q$ is a gel fraction content of initial PEUA network (values varied in the range of 95.297.3 for different PEUA networks).

Swollen samples have been dried at appropriate conditions on air at ambient temperature followed by heating in oven at $90^{\circ} \mathrm{C}$ for $3 \mathrm{hrs}$. The scheme of possible interactions (according to literature data [22]) between $\mathrm{Ti}\left(\mathrm{OiC}_{3} \mathrm{H}_{7}\right)_{4}$ precursor and functionalized polymer network is presented below (Figure 2). Water traces (in the PEUA network or in the solvents used) induces the condensation processes between grafted (onto PEUA chains) and/or 'free' $\mathrm{Ti}\left(\mathrm{OiC}_{3} \mathrm{H}_{7}\right)_{4}$ molecules that always result in polyalkoxytitanate chains bonded with main organic chains of PEUA network.

Hydrolysis of polyalkoxytitanate $\left(\left[-\mathrm{OTi}\left(\mathrm{OC}_{3} \mathrm{H}_{7}\right)_{2}-\right]_{\mathrm{n}}\right)$ chains covalently joined with poly(ether-urethane)acrylate network was performed in boiling water for an appropriate time (experimentally determined) followed by drying in oven at $110^{\circ} \mathrm{C}$ to constant weight. The samples composition and their main characteristics are summarized in Table 2. Quantity of $\mathrm{TiO}_{2}$ adsorbed by PEUA network was determined by Equation (2):

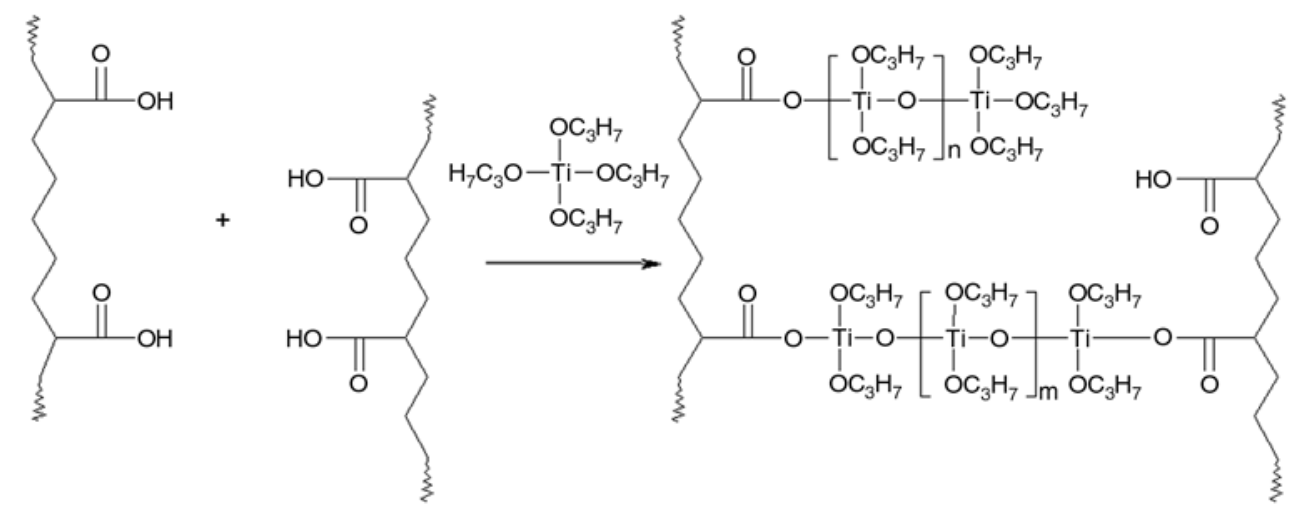

Figure 2. Reaction between $\mathrm{COOH}$-functionalized polymer network (A1-A6 samples) and TIPT precursor 
Table 2. Composition and characteristics of hybrids prepared

\begin{tabular}{|c|c|c|c|c|c|c|c|c|}
\hline $\begin{array}{l}\text { Sample } \\
\text { code }\end{array}$ & Composition & $\begin{array}{c}\text { Gel } \\
\text { content } \\
{[\%]}\end{array}$ & $\begin{array}{l}\text { Treatment } \\
\text { conditions }\end{array}$ & $\begin{array}{c}\text { Swelling } \\
\text { ratio, SR } \\
{[\%]}\end{array}$ & $\begin{array}{c}\mathrm{TiO}_{2} \\
\text { content } \\
{[\mathrm{wt} \%]}\end{array}$ & $\begin{array}{c}\text { TIPT } \\
\text { adsorbeda }^{\text {ad }} \\
{[\mathrm{mg}]}\end{array}$ & $\begin{array}{c}\text { Molar } \\
\text { AA/TIPT } \\
\text { ratio }\end{array}$ & $\begin{array}{c}\text { Trans- } \\
\text { parency }\end{array}$ \\
\hline $\mathrm{A} 1$ & \multirow{3}{*}{ PEUA-1/AA/MMA } & \multirow{3}{*}{95} & TIPT/2-P; 2 hrs & 12 & 3.8 & 139.5 & $1 / 0.35$ & $\mathrm{~T}$ \\
\hline A2 & & & TIPT/2-P; 24 hrs & 55 & 10.4 & 411.0 & $1 / 1.04$ & $\mathrm{~S}$ \\
\hline A3 & & & TIPT/1,4-D; 24 hrs & 120 & 13.6 & 560.8 & $1 / 1.42$ & $\mathrm{~S}$ \\
\hline A4 & \multirow{2}{*}{ PEUA-2/AA/MMA } & \multirow{2}{*}{96} & TIPT/1,4-D; 24 hrs & 250 & 22.7 & 1046.6 & $1 / 2.65$ & $\mathrm{~S}$ \\
\hline A5 & & & TIPT/1,4-D; 72 hrs & 300 & 30.8 & 1587.1 & $1 / 4.02$ & $\mathrm{~S}$ \\
\hline A6 & PEUA-3/AA/MMA & 97 & TIPT/1,4-D; 24 hrs & 153 & 19.4 & 854.0 & $1 / 2.16$ & $\mathrm{~S}$ \\
\hline A7 & PEUA-2/MAA & 95 & TIPT/1,4-D; 24 hrs & 203 & 16.8 & 719.9 & - & $\mathrm{N}$ \\
\hline
\end{tabular}

aQuantity of adsorbed TIPT [mg] per unit weight [1 g] of PEUA network

${ }^{\mathrm{b}} \mathrm{T}$ - transparent; $\mathrm{S}$ - semitransparent; $\mathrm{N}$ - non-transparent; before swelling the polymer networks are fully transparent

$$
w_{T i O_{2} a b s}=\left(\frac{100 m_{c}}{m_{0} q}-1\right) \cdot 100 \%
$$

where $w_{\mathrm{TiO}_{2}} a b s$ and $m_{c}$ are the quantity of $\mathrm{TiO}_{2}$ adsorbed $[\mathrm{wt} \%]$ and final composite film weight after complex treatment (swelling $\rightarrow$ drying $\rightarrow$ hydrolysis $\rightarrow$ drying) [g], respectively. Quantity of TIPT adsorbed was calculated by Equation (3):

$$
m_{\text {TIPTads }}=\frac{1000 \cdot w_{\mathrm{TiO}_{2} a b s} \cdot M_{T I P T}}{\left(100-w_{\mathrm{TiO}_{2} a b s}\right) \cdot M_{T i O_{2}}}
$$

where $m_{\text {TIPTads }}$ is the $\mathrm{Ti}\left(\mathrm{OiC}_{3} \mathrm{H}_{7}\right)_{4}$ weight of chemically adsorbed (bonded) by PEUA network [mg], $M_{T I P T}$ and $M_{T i O_{2}}$ are the molecular weights of TIPT and $\mathrm{TiO}_{2}$, correspondingly.

During hydrolysis of polyalkoxytitanate chains the condensation and aggregation processes are carried out and hybrid polymer/titania composites with incorporated amorphous $\mathrm{TiO}_{2}$ micro- and nanosized structures and, correspondingly, defined level of heterogeneity are formed $[22,23]$.

\subsection{Samples characterization}

Chemical changes during synthesis of hybrid poly(ether-urethane)acrylate/titania microcomposites were identified via infrared spectral studies of the film samples using Bruker Tensor ${ }^{\mathrm{TM}} 37$ FTIR analyzer in the spectral region of $4000-600 \mathrm{~cm}^{-1}$. For phase heterogeneity (at nano-scale level) characterization a small angle X-ray scattering, SAXS, of the hybrid samples were carried out by slit collimated small angle X-ray camera KRM-1 according to Kratky technique over the scattering angle $2 \Theta=$ $0.08-3.5^{\circ}$ using Ni-filtered $\mathrm{Cu}-\mathrm{K}_{\alpha}$ radiation $(\lambda=$
$0.154 \mathrm{~nm})$. Geometrical adjectives of collimation system satisfied the requirements of the infinite high of X-ray beam [24]. Accomplishment of collimation amendment procedure was performed by Schmidt method [25]. Relative parameters of microheterogeneity, like local heterogeneity range, $l_{p}[26]$, and relative heterogeneity parameter (Porod invariant), $Q$ [27] were determined.

In order to characterize micro- and nano-scale heterogeneity the morphology studies of the composites prepared were performed by JEOL JSM 6060 LA Scanning Electron Microscope (Tokyo, Japan) at an accelerating voltage of $30 \mathrm{kV}$. Before measurements the samples were sputter-coated with gold film of 5-10 nm thickness. Microscopy technique was combined with image analysis in order to quantify the distribution size of the particles (two-dimension analysis).

\section{Results and discussion}

\subsection{Swelling behavior and gravimetry analysis}

Studies of hybrid PEUA/titania materials were carried out using swelling characterization, gravimetry analysis, IR spectroscopy, SAXS and SEM combined with image analysis. Visual observations of the initial polymer networks and their hybrid composite analogues (after TIPT treatment and hydrolysis) were carried out and certain changes are identified. As it was observed the initial polymer networks are fully transparent for visible light, whereas their treated (with TIPT solutions) analogues are characterized by slight transparency reduction. It is important that the aforementioned changes are characteristic of the samples with pen- 
dant carboxylic functionality of the networks, while the A7 composite (based on non-functionalized polymer network) became deep-brown and nontransparent. Apparently, it is connected with enlarged linear dimensions of $\mathrm{TiO}_{2}$ inclusions formed during hydrolysis of physically adsorbed tetraisopropoxytitanate agent within non-functionalized poly(ether-urethane)acrylate network compared to the other samples (based on $\mathrm{COOH}$-containing networks). A quite intensive dyeing of the A7 sample film could be due to redox processes that lead to partial oxidation of organic network and corresponding reduction of $\mathrm{Ti}^{4+}$ into $\mathrm{Ti}^{3+}$. It should be noted that for the other samples (A2-A6) these processes are slightly pronounced.

The basic characteristics of initial polymer networks and composites obtained were determined and the results were summarized and analyzed (see data presented in Table 2). As it was found, all initial poly(ether-urethane)acrylate networks show quite similar level of gel fraction content values in the range of 95.2-97.3\%. At the same time swelling values of these film in different organic solvents (2-P or 1,4-D) are different (from $120 \%$ for PEUA1/AA/MMA to $250 \%$ for PEUA-2/AA/MMA samples at the same treatment conditions), however clear correlation between the swelling ratio and chemical structure or composition was not determined. As it was found the $\mathrm{TiO}_{2}$ content values for all composites range are varied from 3.8 to $30.8 \mathrm{wt} \%$. It is clearly seen, the quantity of $\mathrm{TiO}_{2}$ adsorbed depends on treatment time (in 50\% TIPT solution in different organic media), as presented in

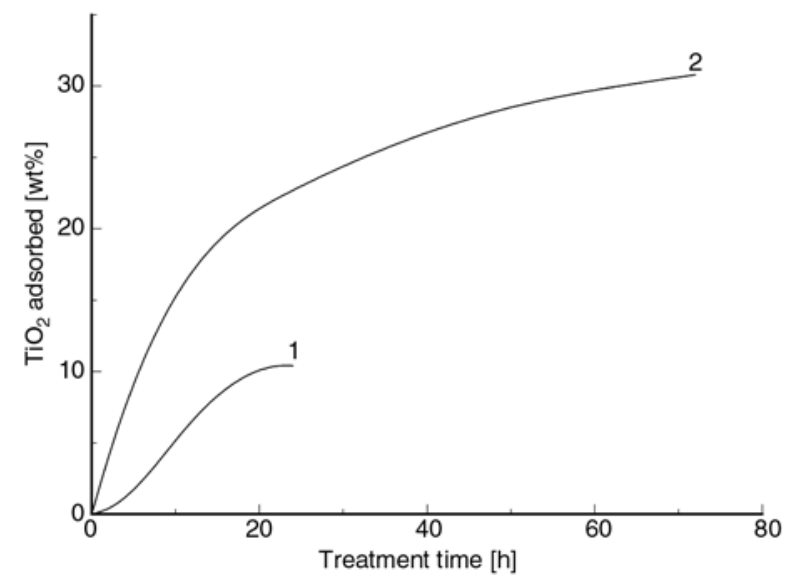

Figure 3. $\mathrm{TiO}_{2}$ content versus treatment time (50\% TIPT solution in different organic media) for microcomposite samples: (1) A1-A2 in 2-propanol, (2) A4-A5 in 1,4-dioxane
Figure 3. In full compliance with the data presented the poly(ether-urethane)acrylate networks shows adequately high level of TIPT adsorption (especially the A5 sample having a maximum treatment time in TIPT solution). It should be noted that relatively low level of TIPT adsorption and $\mathrm{TiO}_{2}$ content in A1 and A2 composites is due to low swelling level of poly(ether-urethane)acrylate networks in 2-P solvent compared to 1,4-D medium (for A1 sample a complex influence of poor swelling agent (2-P) as well as lowest treatment time are found).

Analysis of adsorbed TIPT content and molar AA/TIPT ratio data in the hybrid microcomposites shows their direct correlation with treatment time. Clearly, the increasing treatment time of PEUA networks increases the quantity of TIPT adsorbed, probably, due to increasing of $\mathrm{Ti}\left(\mathrm{OiC}_{3} \mathrm{H}_{7}\right)_{4}$ bonded with PEUA networks and extended into grafted $\left[-\mathrm{OTi}\left(\mathrm{OiC}_{3} \mathrm{H}_{7}\right)_{2}-\right]_{\mathrm{n}}$ chains. Highest molar AA/TIPT ratios (2.65 and $4.02 \mathrm{~mol}$ of adsorbed $\mathrm{Ti}\left(\mathrm{OiC}_{3} \mathrm{H}_{7}\right)_{4}$ per $1 \mathrm{~mol}$ of acrylic acid in poly(ether-urethane) crylate network) in full range of hybrid composite prepared were found for A4 (the best result among the composites after 24 hrs treatment in TIPT solution) and A5 (maximum (72 hrs) treatment time) compositions. Additionally, an evidence of grafting and condensation (transformation of single TIPT grafts into polyalkoxytitanate chains) processes of TIPT component is the absence of $\operatorname{Ti}\left(\mathrm{OiC}_{3} \mathrm{H}_{7}\right)_{4}$ sweating (formation of moisture-initiated surface thin coating of whitish TIPT hydrolysis products) onto film sample surface during first stage drying process. Moreover, the presence of isopropyl alcohol in the 1,4-D spent solution (after separation from the TIPT agent) was also determined, but quantitative (chromatography or titration) analysis was not carried out. Thus, on the base of the results presented it can be supposed that a creation of single $-\mathrm{Ti}\left(\mathrm{OC}_{3} \mathrm{H}_{7}\right)_{3}$ grafts onto organic PEUA network chains, their subsequent extension into $\left[-\mathrm{OTi}\left(\mathrm{OC}_{3} \mathrm{H}_{7}\right)_{2}-\right]_{\mathrm{n}}$ chains, as well as exhaustive hydrolysis and aggregation into spatial $-\left[\mathrm{O}-\mathrm{Ti}(\mathrm{O}-)_{2}-\right]_{\mathrm{n}}$ structures of amorphous $\mathrm{TiO}_{2}$ domains occurred. For confirmation of aforementioned facts of hybrid microcomposites formation the spectral and phase investigations, using IR spectroscopy, SAXS and SEM techniques were carried out. 


\subsection{IR characterization of the composites}

IR spectra of initial polymer network (before treatment) and the hybrids prepared (after full treatment cycle; see 2.4. Preparation of polymer/titania hybrids) are presented in Figure 4. Beforehand, it must be noticed that chemical composition and structures of initial poly(ether-urethane)acrylates and photo-cured ones are quite similar in respect of IR spectroscopy analysis. IR spectrum of initial COOH-functionalized PEUA network of A4 (A5) composition before TIPT treatment was presented and used as a reference curve. The IR spectra of the hybrid composites (A2, A3 and A4) were obtained and analyzed.

As it can be seen the initial polymer network (Figure 4, curve 1) has typical characteristic bands of well-known and well-described in literature poly(ether-urethane)s (poly(ether-urethane)acrylates) [28]. For detailed analysis the most characteristic (for these compositions) bands of $\mathrm{O}-\mathrm{H}(\mathrm{N}-\mathrm{H})$ stretching vibrations in the region of 3500$3200 \mathrm{~cm}^{-1}$ and $\mathrm{C}=\mathrm{O}$ stretching vibration at 1730 $1700 \mathrm{~cm}^{-1}$ have been clearly selected. Here the Gaussian peaks decomposition technique was applied for analysis of relative bands of the spectra to determine any chemical changes of the components during the composites preparation. Additionally, several other characteristic bands in the spectral regions of 3000-2850, 1500-1400 and $\sim 1000 \mathrm{~cm}^{-1}$ were also found.

Detailed Gaussian peaks decomposition analysis of the complex $\mathrm{O}-\mathrm{H}(\mathrm{N}-\mathrm{H})$ and $\mathrm{C}=\mathrm{O}$ bands shows the

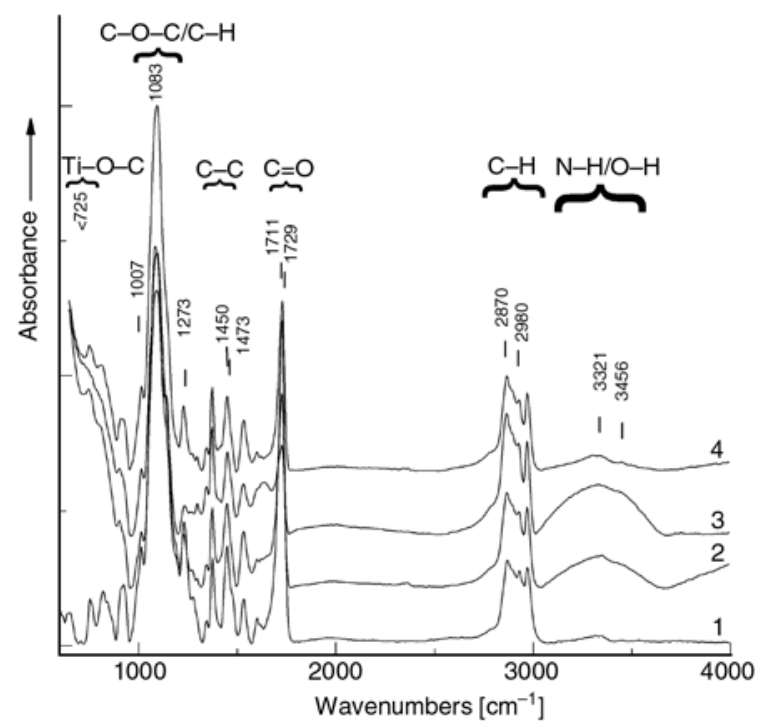

Figure 4. Infrared spectra of initial polymer and the composites prepared: (1) initial A4, (2) A2, (3) A3, (4) A4 following. The main constitution of $\mathrm{O}-\mathrm{H}(\mathrm{N}-\mathrm{H})$ band of initial PEUA network corresponds to $\mathrm{H}$ bonded $\mathrm{N}-\mathrm{H}$ stretching vibration of urethane component centered at $3321 \mathrm{~cm}^{-1}$. Low intensity stretching vibration of 'free' $\mathrm{N}-\mathrm{H}$ groups and/or $\mathrm{O}-\mathrm{H}$ groups of carboxyls at $3456 \mathrm{~cm}^{-1}$ was also observed [29]. Complex $\mathrm{C}=\mathrm{O}$ band could be divided at least on two peaks centered at $1711 \mathrm{~cm}^{-1}$ $(\mathrm{C}=\mathrm{O}$ stretch of free $\mathrm{COOH}$ groups $)$ and at $1729 \mathrm{~cm}^{-1}$ ( $\mathrm{C}=\mathrm{O}$ stretch of urethane/(meth)acrylates ester groups). It should be noted that relative intensity ratio of characteristic bands of 'free' carboxyls $\mathrm{C}=\mathrm{O}$ and urethane/(meth)acrylate ester $\mathrm{C}=\mathrm{O}$ $\left(\mathrm{I}_{\mathrm{C}=\mathrm{Oc}} / \mathrm{I}_{\mathrm{C}=\mathrm{Ou} / \mathrm{a}}\right.$ ), as well as relative intensity ratio of $\mathrm{O}-\mathrm{H}$ and $\mathrm{N}-\mathrm{H}$ groups $\left(\mathrm{I}_{\mathrm{O}-\mathrm{H}} / \mathrm{I}_{\mathrm{N}-\mathrm{H}}\right.$ ) were used for qualitative analysis of chemical changes within hybrids formed. Other bands of the functional groups having a secondary importance for current IR spectra analysis have been also detected in the IR spectrum of initial PEUA. Namely, the sharp medium intensity bands at 2970 and $2870 \mathrm{~cm}^{-1}$ are attributed to $\mathrm{C}-\mathrm{H}$ stretching vibration of methylene groups of oligoether segments. Aromatic constituent of the polyurethane is revealed by multiple weak bands at 1473 and $1450 \mathrm{~cm}^{-1}$ (C-C bonds), as well as at 1273 and $1007 \mathrm{~cm}^{-1}$ (C-H bonds). The high intensity band at $1083 \mathrm{~cm}^{-1}$ was attributed to $\mathrm{C}-\mathrm{O}-\mathrm{C}$ ether linkage of oligoether constituent of poly(ether-urethane)acrylate network.

In IR spectra of the $\mathrm{TiO}_{2}$-containing hybrid composites (Figure 4, curves 2-4) well-defined changes can be seen related to the presence of dispersed $\mathrm{TiO}_{2}$ inclusions formed inside polymer network. Analysis of IR spectra of hybrid composites shows the definite changes of absorption bands of the initial PEUA network. First of all, a significant intensity increasing and wavenumber position shifts of $\mathrm{N}-\mathrm{H}$ (by 2-12 $\mathrm{cm}^{-1}$ ) and $\mathrm{O}-\mathrm{H}$ bands (by 7-1 $9 \mathrm{~cm}^{-1}$ ) were found because of redistribution of the proper H-bonds network of the pure PEUA component when the inorganic $\left(\mathrm{TiO}_{2}\right)$ component introduced as well as an appearance of other functional groups (like $\mathrm{O}-\mathrm{H}$ groups on titania surface that play a definite role in $\mathrm{O}-\mathrm{H}$ band intensity) of new inorganic component was determined. The band corresponds to $\mathrm{O}-\mathrm{H}$ groups of the 'free' carboxyls disappeared (at $3456 \mathrm{~cm}^{-1}$ ) and new characteristic band of $\mathrm{O}-\mathrm{H}$ having another nature (at $3445-$ $3450 \mathrm{~cm}^{-1}$ ) observed. The increasing $\mathrm{I}_{\mathrm{O}-\mathrm{H}} / \mathrm{I}_{\mathrm{N}-\mathrm{H}}$ ratio in the range initial PEUA $\rightarrow$ hybrid compos- 
Table 3. FTIR analysis (Gaussian) of complex $\mathrm{O}-\mathrm{H}(\mathrm{N}-\mathrm{H})$ and $\mathrm{C}=\mathrm{O}$ bands of the hybrid composites

\begin{tabular}{|c|c|c|c|c|c|c|c|c|c|c|}
\hline \multirow[b]{3}{*}{ Sample } & \multicolumn{4}{|c|}{$\mathbf{C}=\mathbf{O}$} & \multirow[b]{3}{*}{$\mathbf{I}_{\mathbf{C}=\mathbf{O c}} / \mathbf{I}_{\mathbf{C}=\mathbf{O u} / \mathbf{a}}$} & \multirow{2}{*}{\multicolumn{2}{|c|}{$\mathbf{N}-\mathbf{H}$}} & \multirow{2}{*}{\multicolumn{2}{|c|}{ O-H }} & \multirow[b]{3}{*}{$\mathrm{I}_{\mathrm{O}-\mathrm{H}} / \mathrm{I}_{\mathrm{N}-\mathrm{H}}$} \\
\hline & \multicolumn{2}{|c|}{ [carboxyl] } & \multicolumn{2}{|c|}{ [urethane/acrylate] } & & & & & & \\
\hline & $\begin{array}{c}\text { position } \\
{\left[\mathrm{cm}^{-1}\right]}\end{array}$ & $\begin{array}{c}\text { relative } \\
\text { intensity, } \\
\mathbf{I}_{\mathbf{C}=\mathbf{O c} \text { [a.u.] }}\end{array}$ & $\begin{array}{c}\text { position } \\
{\left[\mathrm{cm}^{-1}\right]}\end{array}$ & $\begin{array}{c}\text { relative } \\
\text { intensity, } \\
\mathbf{I}_{\mathrm{C}=\mathrm{Ou} / \mathrm{a}}[\mathrm{a.u} .]\end{array}$ & & $\begin{array}{c}\text { position } \\
{\left[\mathrm{cm}^{-1}\right]}\end{array}$ & $\begin{array}{c}\text { relative } \\
\text { intensity, } \\
\mathbf{I}_{\text {N-H }} \text { [a.u.] }\end{array}$ & $\begin{array}{c}\text { position } \\
{\left[\mathrm{cm}^{-1}\right]}\end{array}$ & $\begin{array}{c}\text { relative } \\
\text { intensity, } \\
\text { Io-H [a.u.] }\end{array}$ & \\
\hline Initial $A^{a}$ & 1711 & 0.147 & 1729 & 0.230 & 0.64 & 3321 & 0.006 & 3456 & 0.002 & 0.33 \\
\hline $\mathrm{A} 2$ & 1710 & 0.095 & 1729 & 0.156 & 0.61 & 3323 & 0.036 & 3437 & 0.027 & 0.75 \\
\hline A3 & 1712 & 0.043 & 1730 & 0.077 & 0.56 & 3331 & 0.056 & 3346 & 0.048 & 0.85 \\
\hline A4 & 1711 & 0.068 & 1729 & 0.141 & 0.48 & 3333 & 0.016 & 3449 & 0.008 & 0.50 \\
\hline
\end{tabular}

apure PEUA network

ites evidenced of organic-inorganic hybrids formation. One can supposed an abnormally high intensity of $\mathrm{O}-\mathrm{H}$ band can be evidenced of incomplete isopropyl alcohol elimination from relatively dense organic-inorganic network of A2 and A3 composites compared to initial PEUA network. Similar conclusions can be drawn when the analysis of complex $\mathrm{C}=\mathrm{O}$ characteristic bands was carried out. As it was found the position of corresponding $\mathrm{C}=\mathrm{O}$ bands is practically the same while their intensity substantially changed. Actually, the relative intensity $\mathrm{I}_{\mathrm{C}=\mathrm{OC}} / \mathrm{I}_{\mathrm{C}=\mathrm{Ou} / \mathrm{a}}$ ratio is gradually decreased when the $\mathrm{TiO}_{2}$ content in the range of initial PEUA $\rightarrow$ $\mathrm{A} 2 \rightarrow \mathrm{A} 3 \rightarrow \mathrm{A} 4$ is increased. It is an evidence of decreasing 'free' $\mathrm{COOH}$ content in the composites prepared due to their participation in chemical interactions with initial inorganic constituent $\left(\mathrm{Ti}\left(\mathrm{OiC}_{3} \mathrm{H}_{7}\right)_{4}\right)$. Additionally, the appearance of a new broad and high intensity $\mathrm{Ti}-\mathrm{O}$ stretch in the wavenumber region of lower $725 \mathrm{~cm}^{-1}$ (a shoulder of the mentioned peak is presented in Figure 4, curves 2-4) in the composite samples was observed. The shifts or redistribution of the intensities of other functional groups of organic constituent, namely aliphatic and aromatic $\mathrm{C}-\mathrm{C}$ and $\mathrm{C}-\mathrm{H}, \mathrm{C}-\mathrm{O}-\mathrm{C}$ ether, etc., which do not take part in any interactions during hybrid composites formation practically were not observed. Thus, detailed IR analysis of the microcomposites prepared allowed to confidently concluded that the chemical interactions between carboxyl groups of poly(ether- urethane)acrylate networks and $\operatorname{Ti}\left(\mathrm{OiC}_{3} \mathrm{H}_{7}\right)_{4}$ precursor are carried out and formation of the organicinorganic hybrids occurred.

\subsection{SAXS measurements}

To investigate the microheterogeneity level of the hybrid composites prepared SAXS measurements were carried out on initial PEUA, samples with higher $\mathrm{TiO}_{2}$ inclusions contents as well as pure amorphous $\mathrm{TiO}_{2}$ prepared using standard sol-gel technique [30], and the results are reported in Figure 5 and Table 4 . Clearly, the diffractogram presented shows that the initial components and hybrid

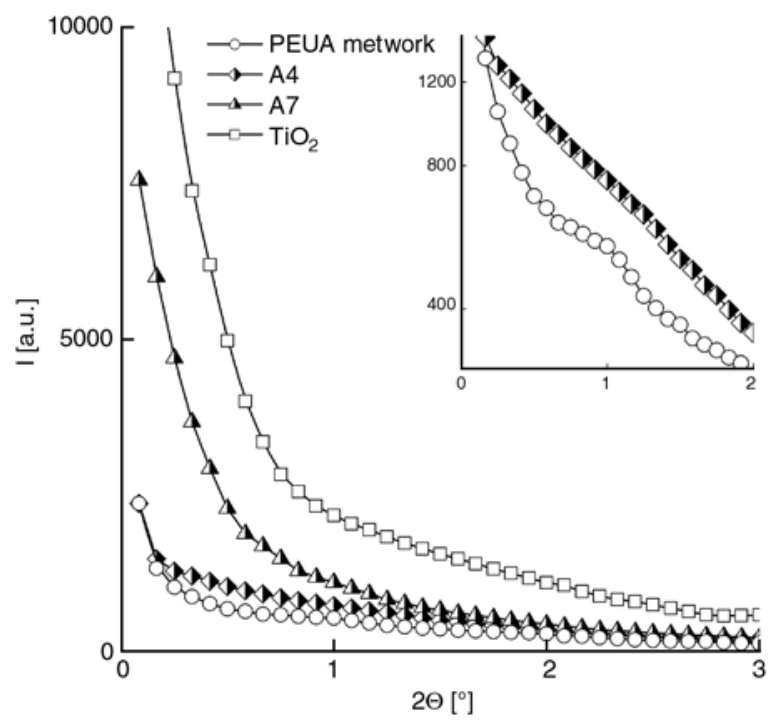

Figure 5. SAXS diffractograms of initial components and selected polymer/titania hybrids

Table 4. SAXS and SEM data of initial PEUA and hybrid A4 and A7 microcomposites

\begin{tabular}{|c|c|c|c|c|c|}
\hline \multirow{2}{*}{ Sample } & \multicolumn{2}{|c|}{ SAXS } & \multicolumn{3}{c|}{ SEM; particle size $[\mu \mathrm{m}]$} \\
\cline { 2 - 6 } & $\mathbf{l}_{\mathbf{p}}[\mathbf{n m}]$ & $\mathbf{Q}[\mathbf{a . u .}]$ & $\mathbf{m i n}$ & $\mathbf{m a x}$ & main fraction \\
\hline Initial PEUA network & 8.4 & 9.8 & - & - & - \\
\hline A4 & 5.0 & 11.2 & 0.17 & $2.50^{\mathrm{a}}$ & $0.90-1.71$ \\
\hline A7 & 3.5 & 14.6 & 0.11 & 7.02 & $0.11-7.02$ \\
\hline
\end{tabular}

a a presence of $\mathrm{TiO}_{2}$ particle with size of $\sim 2.9 \mu \mathrm{m}$ was detected as anomalous 
composite samples obtained exhibit a strongly pronounced level of heterogeneity. As it can be seen the SAXS diffractograms obtained have a typical exponential dependence for the composites with relatively high polydispersity level of heterogeneous regions in nano-scale level. Clearly, that amorphous $\mathrm{TiO}_{2}$ has typical (for low-molecular substances) high scattering intensity level in full $2 \Theta$ range and does not have any peaks on the SAXS curve due to absence of well-defined nanoscaled structural features. Otherwise, for initial PEUA network as well as for the hybrid composites the some similar peculiarities were found. Detailed analysis of SAXS curves of initial PEUA network and A4 hybrid at high resolution condition (Figure 5, high resolution supplement) shows a broad flat peak centered at $2 \Theta \approx 1^{\circ}$. For A7 sample an existence of this peak is also considered (at a little higher $2 \Theta$ ) but it is not so appreciable. It can be evidence of slight predominance of one closely-sized nanoheterogeneous regions over the other ones. Mathematical treatment of these plots is allowed to calculate a characteristic size of nanoheterogeneity regions, $l_{p}$, for the samples. Specifically, $l_{p}$ values for A4 and A7 composites was found as 5.0 and $3.5 \mathrm{~nm}$, respectively, compared to $8.4 \mathrm{~nm}$ for initial PEUA network. As it will be shown below (SEM measurements) these values do not reflect a real heterogeneity of the hybrid composites and characterize exceptionally nano-scale heterogeneity (phase separation) level of typical poly(ether-urethane)acrylates. Another method of heterogeneity characterization was also applied and described using Porod invariant. Actually, as it was calculated, the Porod invariant values, $Q$, for initial PEUA network, A4 and A7 hybrids were about 9.8, 11.2 and 14.6 relative units, respectively. Thus, A7 hybrid composition (based on non-functionalized poly(ether-urethane)acrylate) has a higher heterogeneity level compared to the A4 hybrid, and, correspondingly, pure PEUA network (Table 4). Additionally, it should be noted that the A7 composite sample has a higher intensity of scattering compared to $\mathrm{A} 4$ composite in the full range of $2 \Theta$ scale (up to $2 \Theta=3^{\circ}$ ) that can be also due to higher heterogeneous regions content.

Summarizing the foregoing facts it can be concluded that the microcomposite samples prepared are characterized by well-defined nanoheterogeneity level. Increasing phase separation processes and formation of smaller nano-scaled heterogeneous regions occur while the amorphous $\mathrm{TiO}_{2}$ agglomerates are formed inside organic PEUA network. An evidence of heterogeneous character of the hybrid composites in micro-scale level will be shown below using their morphology studies by SEM.

\subsection{Morphology characterization}

The surface morphology of the aforementioned hybrid composites was investigated and SEM microphotographs and basic heterogeneity characteristics were presented in Figures 6, 7 and Table 4, correspondingly. First, as it could be seen from Figure 6, a-d formation of the hybrid composites is accompanied by partial fracturing of the samples because of internal tension excess during formation and enlargement of inorganic $\mathrm{TiO}_{2}$ inclusions. The morphology analysis of A4 composite (Figure 6a6 b; Figure 7, curve 1) shows relatively low polydispersity level of dispersed phase with $\mathrm{TiO}_{2}$ particle size from 2.50 to $0.17 \mu \mathrm{m}$ and, probably, even lower (as an evidence of significant sample transparency). The dominant $\mathrm{TiO}_{2}$ fraction dispersed in polymer network was about $0.90-1.70 \mu \mathrm{m}$, whereas the presence of large particles with linear dimension at $\sim 3 \mu \mathrm{m}$ is atypical (see Table 4; Figure 7, curve 1). It should be noted that for A4 hybrid relatively uniform $\mathrm{TiO}_{2}$ aggregates distribution in the sample volume was found. As an interesting fact of SEM studies, the ball-shaped dispersed titania particles (single or aggregates) were mainly observed for this composition (Figure 6a-6b).

Otherwise, A7 hybrid (Figure 6c-6d) is characterized by uniform $\mathrm{TiO}_{2}$ particles distribution with particle linear dimension size in the range of 0.1$7.0 \mu \mathrm{m}$ (Table 4; Figure 7, curve 2). It is important that there are no any possibilities to determine the dominant fraction of $\mathrm{TiO}_{2}$ inclusions in $\mathrm{A} 7$ hybrid sample due to quite broad particle size range. Moreover, irregular shape types of titania inclusions are typical for this composite based on nonfunctionalized organic poly(ether-urethane) acrylate constituent. It could be also seen that volume distribution of $\mathrm{TiO}_{2}$ aggregates formed in $\mathrm{A} 7 \mathrm{com}$ position is mainly random (Figure 6c-6d).

Thus, it can be concluded that typical hybrid polymer/titania composites using a swelling approach for hybrids synthesis were prepared and the samples obtained were studied in details. Carboxyl 

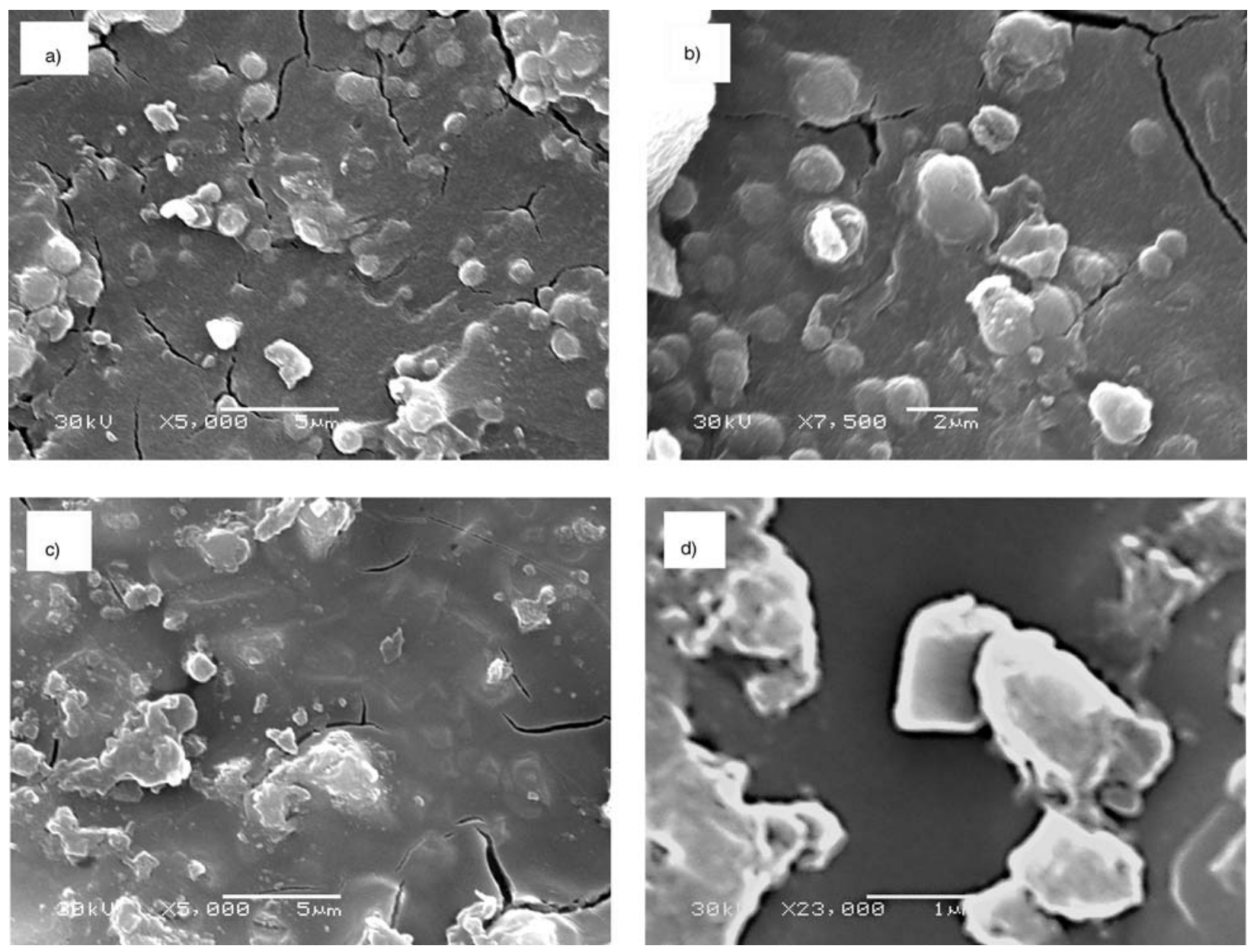

Figure 6. SEM microphotographs of hybrid composites prepared: (a, b) A4; (c, d) A7

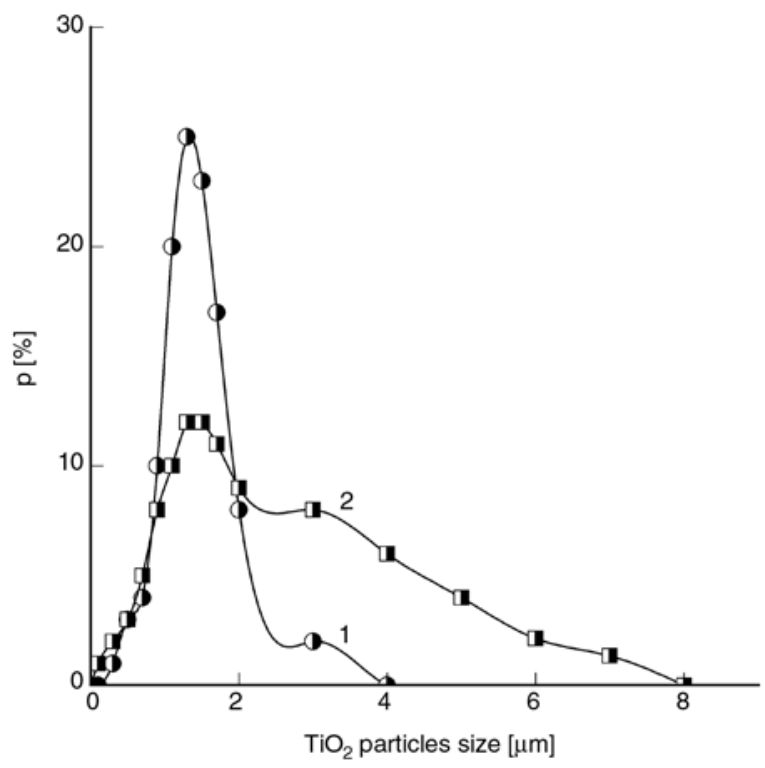

Figure 7. $\mathrm{TiO}_{2}$ particles size distribution for microcomposites based on $\mathrm{COOH}$-functionalized (1; A4 sample) and non-functionalized (2; A7 sample) networks

functionality of polymer chain playing a role of covalent bonding sites for inorganic $\mathrm{Ti}\left(\mathrm{OiC}_{3} \mathrm{H}_{7}\right)_{4}$ component and organic PEUA chains has a significant influence on inorganic aggregates distribution in the film samples as well as on $\mathrm{TiO}_{2}$ particles shape. Additionally, the samples with pendant $\mathrm{COOH}$ functional groups are characterized by narrow titania particles size distribution.

\section{Conclusions}

Summarizing of the experimental results presented in this work is allowed to conclude the follow. Synthesis of polymer/titania hybrid microcomposites via swelling of poly(ether-urethane)acrylate polymer network in concentrated solution of tetraisopropoxytitanate in 2-propanol or, that was found as more effective, 1,4-dioxane organic media were carried out. The composites prepared were characterized via IR, SAXS and SEM techniques, as well as their gravimetric parameters and swelling behavior in details. Gravimetric analysis shown that $\mathrm{TiO}_{2}$ content in the most polymer composites prepared was found in the range of 3.8-30.8 wt $\%$. SAXS 
studies are evidenced of nano-sized $(3.5-5 \mathrm{~nm})$ heterogeneity of the polymer/ $\mathrm{TiO}_{2}$ composites prepared, that is typical for initial PEUA network. Using IR studies the formation of the hybrid microcomposites via chemical interactions of high reactive carboxylic groups of poly(ether-urethane) acrylate constituent and $\mathrm{Ti}\left(\mathrm{OiC}_{3} \mathrm{H}_{7}\right)_{4}$ precursor was clearly confirmed. Thus, the presence of functional (pendant $\mathrm{COOH}$ ) groups in photo-cured polymer (PEUA) matrix exerts primary influence on a formation of the hybrids. Functionality of initial poly(ether-urethane)acrylate networks in relation with tetraalkoxytitanate precursor has a direct influence on both microscopic $\left(\mathrm{TiO}_{2}\right.$ particles size distribution, shape of the $\mathrm{TiO}_{2}$ aggregates) and macroscopic (transparency) properties of the composites obtained. The ball-shaped dispersed titania particles (separated or aggregated) were mainly observed for composition based on carboxyl-functionalized poly(ether-urethane)acrylate network. Moreover, a relatively wide $\mathrm{TiO}_{2}$ particles size distribution (in the range of 0.1-7.0 $\mu \mathrm{m}$ ) for non-functionalized network and narrower $\mathrm{TiO}_{2}$ particles size distribution (0.9-1.71 $\mu \mathrm{m}$; main fraction) for $\mathrm{COOH}$-functionalized polymer network were found for the microcomposites obtained.

Finally, the experimental data obtained in this work could be used for elaboration of high-loaded transparent or semitransparent $\mathrm{TiO}_{2}$-filled hybrid polymer materials for multipurpose optical uses or advanced sealants.

\section{References}

[1] Armelao L., Barreca D., Bottaro G., Gasparotto A., Gross S., Maragno C., Tondello E.: Recent trends on nanocomposites based on $\mathrm{Cu}, \mathrm{Ag}$ and Au clusters: A closer look. Coordination Chemistry Reviews, 250, 1294-1314 (2006).

[2] Li W., Jia Q. X., Wang H-L.: Facile synthesis of metal nanoparticles using conducting polymer colloids. Polymer, 47, 23-26 (2006).

[3] García-Gutiérrez M. C., Nogales A., Rueda D. R., Domingo C., García-Ramos J. V., Broza G., Roslaniec Z., Schulte K., Davies R. J., Ezquerra T. A.: Templating of crystallization and shear-induced self-assembly of single-wall carbon nanotubes in a polymer-nanocomposite. Polymer, 47, 341-345 (2006).
[4] Peeterbroeck S., Alexandre M., Jerome R., Dubois P.: Poly(ethylene-co-vinyl acetate)/clay nanocomposites: Effect of clay nature and organic modifiers on morphology, mechanical and thermal properties. Polymer Degradation and Stability, 90, 288-294 (2005).

[5] Dangtungee R., Yun J., Supaphol P.: Melt rheology and extrudate swell of calcium carbonate nanoparticle-filled isotactic polypropylene. Polymer Testing, 24, 2-11 (2005).

[6] Wu L., Chen P., Zhang J., He J.: Inhibited transesterification and enhanced fibrillation of TLCP by nano$\mathrm{SiO}_{2}$ in polycarbonate matrix. Polymer, 47, 448-456 (2006).

[7] Kudaibergenov S. E., Tatykhanova G. S., Arinov B. Zh., Kozhakhmetov S. K., Aseyev V. O.: Hybrid inorganic-organic nano- and microcomposites based on silica sols and synthetic polyelectrolytes. Express Polymer Letters, 2, 101-110 (2008).

[8] Bauer F., Decker U., Ernst H., Findeisen M., Langguth H., Mehnert R., Sauerland V., Hinterwaldner R.: Functionalized inorganic/organic nanocomposites as new basic raw materials for adhesives and sealants. Part 2. International Journal of Adhesion and Adhesives, 26, 567-570 (2006).

[9] Chang C-C., Chen W-C.: High-refractive-index thin films prepared from aminoalkoxysilane-capped pyromellitic dianhydride-titania hybrid materials. Journal of Polymer Science Part A: Polymer Chemistry, 39, 3419-3427 (2001).

[10] Coutinho C. A., Gupta V. K.: Formation and properties of composites based on microgels of a responsive polymer and $\mathrm{TiO}_{2}$ nanoparticles. Journal of Colloid and Interface Science, 315, 116-122 (2007).

[11] Iketani K., Sun R-D., Toki M., Hirota K., Yamaguchi O.: Sol-gel-derived $\mathrm{TiO}_{2} /$ poly(dimethylsiloxane) hybrid films and their photocatalytic activities. Journal of Physics and Chemistry of Solids, 64, 507-513 (2003).

[12] Xiong M., You B., Zhou S., Wu L.: Study on acrylic resin/titania organic-inorganic hybrid materials prepared by the sol-gel process. Polymer, 45, 2967-2976 (2004).

[13] Syzdek J., Borkowska R., Perzyna K., Tarascon J. M., Wieczorek W.: Novel composite polymeric electrolytes with surface-modified inorganic fillers. Journal of Power Sources, 173, 712-720 (2007).

[14] Katsaros G., Stergiopoulos T., Arabatzis I. M., Papadokostaki K. G., Falaras P.: A solvent-free composite polymer/inorganic oxide electrolyte for high efficiency solid-state dye-sensitized solar cells. Journal of Photochemistry and Photobiology A: Chemistry, 149, 191-198 (2002).

[15] Chatzivasiloglou E., Stergiopoulos T., Spyrellis N., Falaras P.: Solid-state sensitized solar cells, using $\left[\mathrm{Ru}\left(\mathrm{dcbpyH}_{2}\right)_{2} \mathrm{Cl}_{2}\right] \cdot 2 \mathrm{H}_{2} \mathrm{O}$ as the dye and $\mathrm{PEO} /$ titania/ $\mathrm{I}^{-} / \mathrm{I}_{3}{ }^{-}$as the redox electrolyte. Journal of Materials Processing Technology, 161, 234-240 (2005). 
[16] Hattori H.: Two-step assembly technique for preparation of polymer-particle composite films. Thin Solid Films, 385, 302-306 (2001).

[17] Chau J. L. H., Lin Y-M., Li A-K., Su W-F., Chang KS., Hsu S. L-C., Li T-L.: Transparent high refractive index nanocomposite thin films. Materials Letters, 61, 2908-2910 (2007).

[18] Kizilkaya C., Karataş S., Kayaman-Apohan N., Güngör A.: Preparation and characterization of sol-gel derived UV-curable organo-silica-titania hybrid coatings. Progress in Organic Coatings, 60, 140-147 (2007).

[19] Luo X., Zha C., Luther-Davies B.: Preparation and optical properties of titania-doped hybrid polymer via anhydrous sol-gel process. Journal of Non-Crystalline Solids, 351, 29-34 (2005).

[20] Naylor S., Bras W., Derbyshire G., Mant G. R., Bogg D., Ryan A. J.: Simultaneous time-resolved synchrotron X-ray scattering studies on block copoly(etherurethane) phase behaviour. Nuclear Instruments and Methods in Physics Research, Section B: Beam Interactions, 97, 253-256 (1995).

[21] Ferrer G. G., Pradas M. M., Ribelles J. L. G.: Thermodynamics of water sorption in acrylic homonetworks and IPNs. Die Makromolekulare Chemie, Macromolecular Symposia, 200, 217-225 (2003).

[22] Feld R., Cowe P. L.: The organic chemistry of titanium. Butterworths, London (1965).
[23] Deshpande S. B., Potdar H. S., Khollam Y. B., Patil K. R., Pasricha R., Jacob N. E.: Room temperature synthesis of mesoporous aggregates of anatase $\mathrm{TiO}_{2}$ nanoparticles. Materials Chemistry and Physics, 97, 207-212 (2006).

[24] Kratky O., Pilz I., Schmitz P. J.: Absolute intensity measurement of small-angle X-ray scattering by means of a standard sample. Journal of Colloid and Interface Science, 21, 24-34 (1966).

[25] Schmidt P. W., Hight R. J.: Slit height corrections in small angle X-ray scattering. Acta Crystallographica, 13, 480-483 (1960).

[26] Perret R., Ruland W.: Eine verbesserte Auswertungsmethode fur die Röntgenkleine-winkelstreuung von Hochpolymeren. Kolloid-Zeitschrift und Zeitschrift für Polymere, 247, 835-843 (1971).

[27] Guinier A., Fourner G.: Small angle scattering of X-rays. John Wiley and Sons, New York (1955).

[28] Tsai Y-M., Yu T-L., Tseng Y-H.: Physical properties of crosslinked polyurethane. Polymer International, 47, 445-450 (1998).

[29] Chen K. S., Yu T. L., Tseng Y. H.: Effect of polyester zigzag structure on the phase segregation of polyesterbased polyurethanes. Journal of Polymer Science, Part A: Polymer Chemistry, 37, 2095-2104 (1999).

[30] Kartini I., Meredith P., Diniz da Costa J. C., Lu G. Q.: A novel route to the synthesis of mesoporous titania with full anatase nanocrystalline domains. Journal of Sol-Gel Science and Technology, 31, 185-189 (2004). 